\title{
Rancang Bangun Sistem Informasi Point of Sales (POS) Pada CV. Arema Alam Abadi
}

\author{
Muhamad Nasihin \\ Universitas Bina Sarana Informatika, Pontianak \\ email: muhamad.mhn@bsi.ac.id
}

\begin{abstract}
ABSTRAK - Teknologi informasi merupakan salah satu teknologi yang berkembang sangat signifikan saat ini. Hampir di semua lini kehidupan, masyarakat sudah banyak memanfaatkan dan menerapkan teknologi informasi untuk mempermudah pekerjaan dan memperlancar aktifitas sehari-hari, baik di lingkungan instansi pemerintahan, pengusaha, maupun masyarakat luas pada umumnya. CV. Arema Alam Abadi merupakan perusahaan yang bergerak di bidang penjualan batu alam. Sistem penjualan yang digunakan saat ini masih berupa pembukuan konvensional. Hal ini menyebabkan kurang efektif dan efesien dalam melakukan proses penjualan dan pelaporan. Dengan pembukuan konvensional tersebut, data yang disajikan kurang akurat, karena pengarsipan data yang masih menggunakan sistem konvensional memiliki resiko tinggi akan kesalahan dan kerusakan data. Maka dari itu Penulis mengusulkan rancangan sistem informasi baru dengan sistem yang terkomputerisasi, dengan harapan dapat membantu mempercepat proses kerja dan meningkatkan keakuratan dalam pengolahan data penjualan dan pelaporan yang berlangsung pada CV. Arema Alam Abadi.
\end{abstract}

Kata Kunci: Sistem Informasi, Point of Sales, Batu Alam

ABSTRACT - Information technology is one technology that is developing very significantly nowadays. In almost all lines of life, many people have used and applied information technology to facilitate work and facilitate daily activities, both within government agencies, entrepreneurs, and the wider community at large. $C V$. Arema Alam Abadi is a company engaged in the sale of natural stone. The sales system used today is still in the form of conventional bookkeeping. This causes less effective and efficient in the sales and reporting process. With conventional bookkeeping, the data presented is less accurate, because archiving data that still uses conventional systems has a high risk of data errors and damage. Therefore Author proposes a new information system design with a computerized system, with the hope that it can help speed up the work process and improve accuracy in processing sales and reporting data that takes place on the CV. Arema of Eternal Nature.

Index Terms: Information System, Point of Sales, Natural Stones 


\section{PENDAHULUAN}

Aktivitas pencatatan transaksi pada CV. Arema Alam Abadi saat ini masih menggunakan cara manual, yaitu menggunakan media kertas yang dibukukan seperti data barang, data pengadaan atau pembelian barang dan data penjualan, kemudian disalin ke Microsoft Excel untuk direkapitulasi menjadi laporan persediaan barang, laporan pengadaan atau pembelian barang dan laporan penjualan. Jika perusahaan membutuhkan informasi tentang ketersediaan barang maka diperlukan waktu yang lama untuk pengecekan di dalam buku besar atau di Microsoft Excel dan memastikan keberadaan barang. Tidak jarang, jumlah stok yang ada di data persediaan barang tidak sesuai dengan data persediaan barang yang dihitung langsung oleh bagian administrasi, dikarenakan beberapa data yang berkaitan dengan data persediaan barang (seperti data pengadaan atau pembelian barang dan penjualan) mengalami kerusakan atau hilang dan kurangnya ketelitian dari bagian administrasi dalam mengkalkulasikan stok barang. Cara seperti ini juga membuat bagian penjualan tidak tahu secara pasti ketersediaan stok barang. Untuk itu dibutuhkan sebuah sistem informasi yang lebih baik untuk dapat mengelola data penjualan dan pelaporan agar menjadi lebih efektif dan efisien.

Berdasarkan permasalahan di atas, maka Penulis berupaya untuk memberikan solusi agar proses pengelolan data penjualan dan pelaporan dapat terlaksana dengan lebih efektif dan efisien, dengan merancang Sistem Informasi Point of Sales (POS) Pada CV. Arema Alam Abadi.

\section{METODOLOGI PENELITIAN}

Metode penelitian yang Penulis gunakan adalah metode deskriptif yang bertujuan untuk mendeskripsikan secara sistematis, faktual dan akurat mengenai fakta-fakta pada objek penelitian dan berdasarkan data yang diperoleh akan dirancang sistem informasi yang diharapkan dapat mengatasi permasalahan yang dihadapi oleh CV. Arema Alam Abadi.

\section{Metode Pengembangan Perangkat Lunak Prototype}

Metode pengembangan perangkat lunak yang digunakan pada penelitian ini adalah metode prototype. Model prototipe cocok digunakan untuk menggali spesifikasi kebutuhan pelanggan secara lebih detil. Model prototype ini memiliki beberapa tahapan, yaitu:

\section{1) Mendengarkan Pelanggan}

Kegiatan ini dikategorikan sebagai analisis kebutuhan untuk mengetahui kebutuhan pengguna dan kebutuhan sistem serta untuk menentukan tujuan umum dan kebutuhan dasar. Pada tahapan ini, penulis melakukan observasi di CV. Arema Alam Abadi dan mewawancarai staf dan karyawan yang akan menjadi user pada sistem yang akan dirancang, sehingga didapatkan gambaran umum sistem berjalan yang sedang digunakan saat ini.

2) Membangun atau Memperbaiki Prototype

Pada tahapan ini, penulis merancang bangun prototype system. Prototype yang dirancang disesuaikan dengan kebutuhan sistem yang telah didefinisikan dari tahapan sebelumnya, sehingga diharapkan sistem yang dihasilkan nantinya sesuai dengan yang diharapkan oleh objek penelitian agar dapat mengatasi permasalahan yang dihadapi ketika menggunakan sistem yang sedang berjalan saat ini.

\section{3) Uji Coba}

Pada tahap ini, prototype dari sistem diuji coba oleh pengguna. Penulis meminta staf dan karyawan CV. Arema Alam Abadi untuk mencoba menggunakan prototype sistem yang telah dibangun, sesuai dengan tingkatan user-nya masingmasing. Kemudian penulis melakukan evaluasi terhadap kekurangankekurangan dari kebutuhan pelanggan berdasarkan hasil uji coba yang telah dilaukan. Setelah dilakukan revisi pada 
prototype sistem yang dibangun, kemudian kembali mendengarkan keluhan dari pelanggan melalui uji coba sistem kembali, untuk memperbaiki prototype yang ada, dan seterusnya, sehingga prototype sistem yang dibangun benar-benar sudah memenuhi keinginan pelanggan agar dapat digunakan sesuai dengan prosedus sistem berjalan saat ini namun dengan segala perbaikan yang diusulkan agar dapat menyelesaikan permasalahan yang dihadapi oleh CV. Arema Alam Abadi dengan lebih efektif dan efisien.

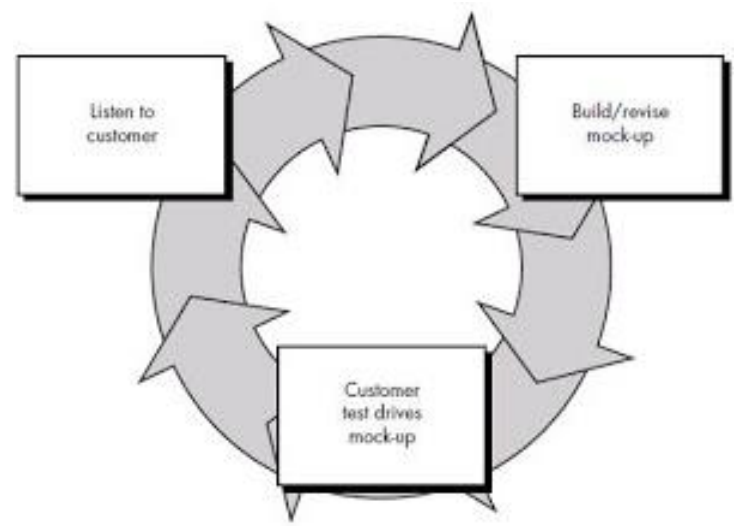

Gambar 1. Ilustrasi Metode Pengembangan Perangkat Lunak Prototype

\section{Teknik Pengumpulan Data}

Agar prototype sistem yang yang dirancang dan dibangun tepat sasaran, maka penulis menggunakan teknik pengumpulan data untuk mendukung proses penelitian ini yaitu:

\section{1) Observasi}

Penulis melakukan observasi pada CV. Arema Alam Abadi yang beralamat di Jl. Arteri Supadio, Kec. Sungai Raya, Kabupaten Kubu Raya, Kalimantan Barat mengenai sistem penjualan dan pembuatan laporan penjualan. Pada tahapan ini, Penulis mengamati secara langsung prosedur sistem berjalan yang digunakan saat ini, sehingga mendapat gambaran yang jelas bagaimana proses yang berlangsung saat ini.

2) Wawancara

Tanya jawab langsung dilakukan dengan Pimpinan Perusahaan dan Staf Administrasi dari CV. Arema Alam Abadi mengenai sistem penjualan dan pelaporan yang digunakan, untuk mengetahui prosedur seperti apa yang diterapkan pada sistem berjalan, bagaimana proses penjualan, siapa saja yang terlibat dalam proses jual beli, dan apa sajan permasalahan yang sering terjadi pada proses penjualan dan pelaporan.

\section{3) Studi Pustaka}

Selain menerapkan teknik pengumpulan data di atas, Penulis juga melakukan studi kepustakaan untuk menambah referensi penelitian melalui buku-buku, jurnaljurnal ilmiah dan artikel-artikal di internet.

\section{HASIL DAN PEMBAHASAN \\ Tahapan Mendengarkan Pelanggan}

Pada tahap ini penulis mengidentifikasi kebutuhan fungsional prototype yang akan dirancang. Sumber informasinya berasal dari hasil observasi dan wawancara yang telah dilaksanakan di CV. Arema Alam Abadi.

\section{1) Kebutuhan Fungsional}

Secara fungsional, pada prototype Sistem Informasi Point of Sales Pada CV. Arema Alam Abadi terdapat beberapa pengguna yang dapat saling berinteraksi dalam lingkungan sistem, yaitu Staf Administrasi, Konsumen, Bagian Gudang, Distributor dan Direktur. Pengguna-pengguna tersebut memiliki karakteristik interaksi dengan sistem dan memiliki kebutuhan informasi yang berbeda, yaitu :

a) Skenario Kebutuhan Staf Admininstrasi

(1) Mengelola data penjualan

(2) Mengelola data konsumen

(3) Mengelola data pesanan

(4) Membuat faktur pembayaran 
(5) Mengelola data pembayaran

(6) Melihat data barang

b) Sekenario Kebutuhan Konsumen

(1) Melakukan registrasi

(2) Melakukan input pemesanan

(3) Melakukan pembayaran

c) Sekenario Kebutuhan Bagian Gudang

(1) Mengelola data barang

(2) Melihat data pesanan

d) Sekenario Kebutuhan Distributor

(1) Melihat dat pembelian

(2) Cetak faktur pembelian

e) Sekenario Kebutuhan Direktur

(1) Mengelola data user

(2) Melihat laporan penjualan

\section{2) Kebutuhan Non Fungsional}

Kebutuhan non fungsional adalah kebutuhan yang meliputi perangkat keras dan perangkat lunak yang sangat mempengaruhi berjalannya program aplikasi. Adapun kebutuhan-kebutuhan non fungsional tersebut meliputi:

a) Perangkat Keras

Perangkat keras adalah perangkat fisik yang digunakan untuk merancang dan membangun prototype Sistem Informasi Point of Sales (POS) Pada CV. Arema Alam Abadi

ini.

Adapun spesifikasi perangkat keras yang dianjurkan sebagai berikut:

(1) Komputer (Processor AMD E11200 [1.40 Ghz], RAM 2.00 GB, Harddisk 120 GB, Monitor 14 Inch dengan Resolusi Layar Min. $1024 \times 768$ )

(2) Mouse

(3) Keyboard

b) Perangkat Lunak

Perangkat lunak adalah program aplikasi yang digunakan untuk merancang dan membangun Sistem Informasi Point of Sales (POS) Pada CV. Arema Alam Abadi ini. Adapun perangkat lunak yang dianjurkan adalah sebagai berikut:

(1) Sistem Operasi Microsoft Windows 7.
(2) Aplikasi XAMPP yang terdiri dari beberapa komponen di dalamnya, yaitu Apache, PHPMyAdmin dan MySQL

(3) Aplikasi Visual Paradigm untuk merancang sistem.

(4) Aplikasi Microsft Visual Studio.NET untuk membangun Sistem Informasi Point of Sales (POS) Pada CV. Arema Alam Abadi.

\section{Membangun atau Memperbaiki Prototype}

\section{1) Rancangan Use Case Diagram}

Untuk memberikan gambaran umum mengenai prototype Sistem Informasi Point of Sales (POS) Pada CV. Arema Alam Abadi yang akan dibangun, maka dirancang use case diagram, sebagai berikut:

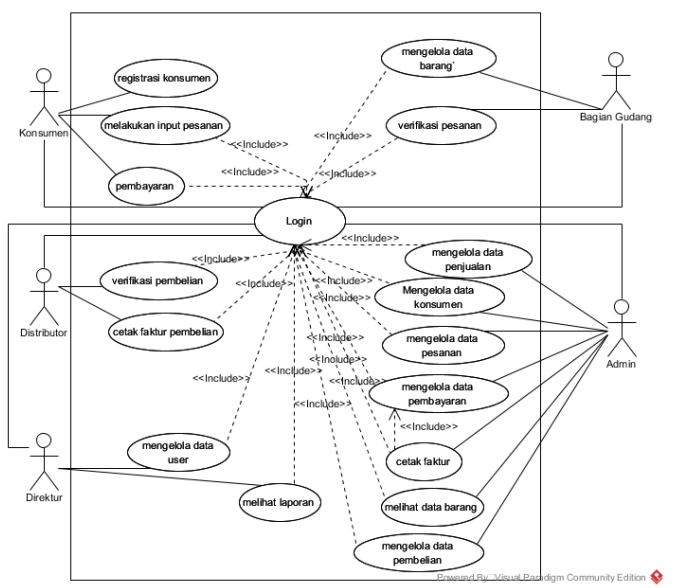

Gambar 2. Use Case Diagram Sistem Informasi Point of Sales (POS) Pada CV. Arema Alam Abadi

Pada Use Case Diagram di atas terdekripsikan dengan jelas apa saja yang dapat dilakukan oleh setiap aktor, sesuai dengan tingkat user-nya masing-masing, yaitu Staf Admininistrasi, Konsumen, Bagian Gudang, Distributor dan juga Direktur, sesuai dengan Kebutuhan Fungsional yang telah dipaparkan pada bagian sebelumnya. Hal ini disebabkan setiap user memang memiliki tugas dan kebutuhan yang berbeda, sesuai dengan peranannya masing-masing pada $\mathrm{CV}$. Arema Alam Abadi, sehingga setiap user hanya dapat mengakses menu-menu yang 
sesuai dengan deskripsi tugasnya masingmasing, tanpa mengganggu dan terganggu oleh deskripsi tugas dari users yang lain.

2) Rancangan Activity Diagram

Diagram aktivitas digunakan untuk memberikan gambaran alur kerja dari prototype Sistem yang dirancang. Setiap tingkat user memiliki aktivitas dan interaksi yang berbeda, sesuai dengan dekripsi tugas dan pekerjaannya masingmasing pada CV. Arema Alam Abadi. Adapun alur kerja masing-masing user dapat dilihat pada activity diagram berikut:

\section{a) Activity Diagram Staf Administrasi}

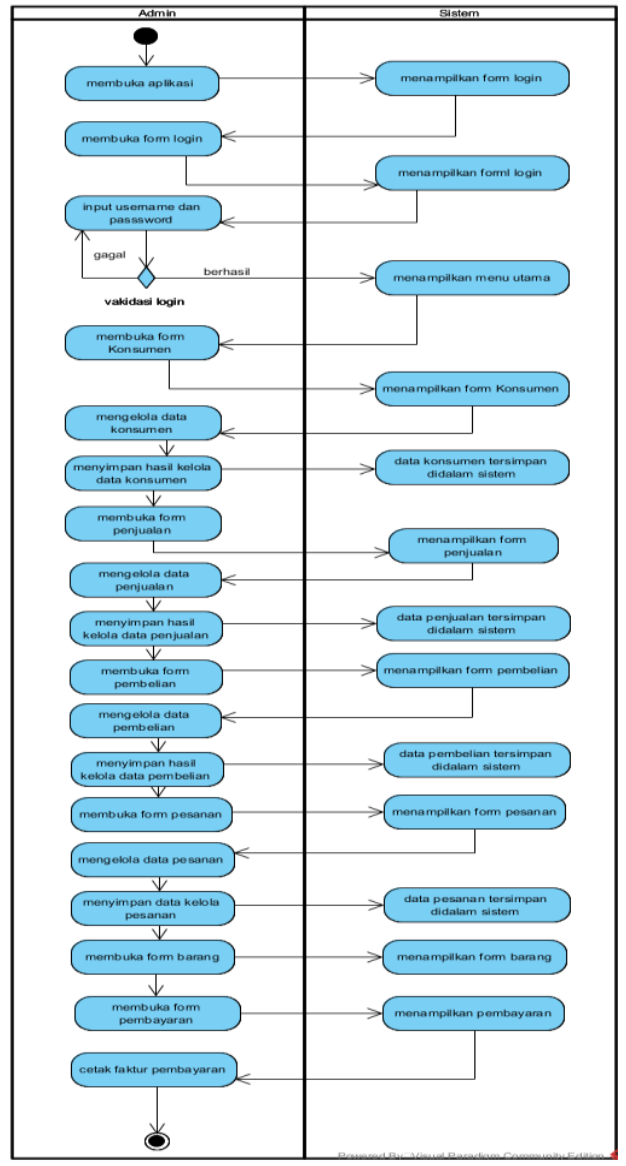

Gambar 3. Activity Diagram

Staf Administrasi

Dari Activity Diagram di atas, dapat diketahui aktivitas apa saja yang dapat dilakukan oleh Staf Administrasi ketika berinteraksi dengan Sistem Informasi Point of Sales (POS) Pada CV. Arema Alam
Abadi. Di sini terlihat jelas aksi dan reaksi yang terjadi ketika Staf Administrasi memberikan perintah pada sistem dan feedback yang diberikan oleh sistem kepada Staf Administrasi. Alur kerja ini bersumber dari hasil observasi dan wawancara Penulis dengan Staf Administrasi.

b) Activity Diagram Konsumen

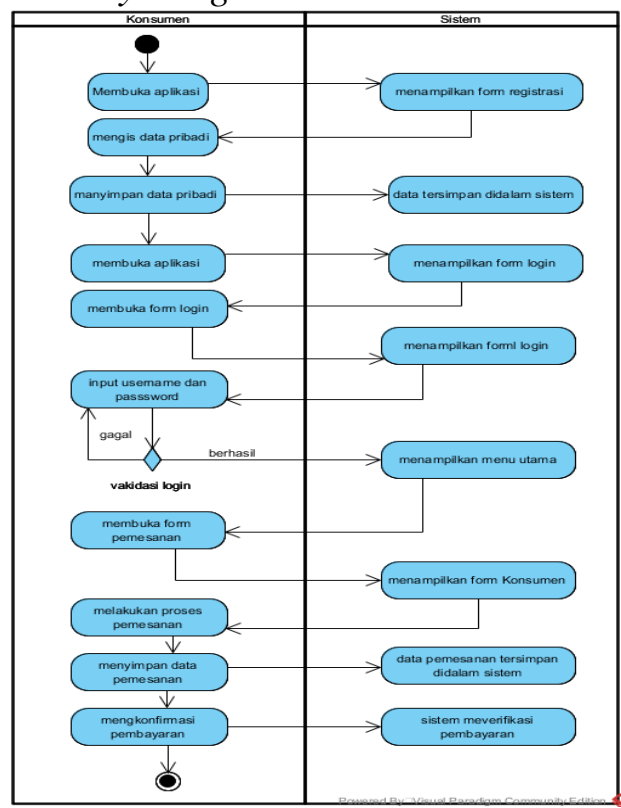

Gambar 4. Activity Diagram Konsumen

Dari Activity Diagram di atas, dapat diketahui bagaimana ketika Konsumen ingin melakukan pemesanan dan mengkonfirmasi pembayaran melalui Sistem Informasi Point of Sales (POS) Pada CV. Arema Alam Abadi. Aktivitas ini dimulai dari membuat akun terlebih dahulu, agar dapat diketahui dengan jelas informasi tentang konsumen ini. Hal ini dimaksudkan untuk mempermudah proses pemesanan, konfirmasi pembayaran dan tentunya pengiriman barang yang dipesan. Karena konsumen yang menginputkan sendiri datanya, tentunya akan meminimalisir kesalahan yang terjadi. 
c) Activity Diagram Bagian Gudang

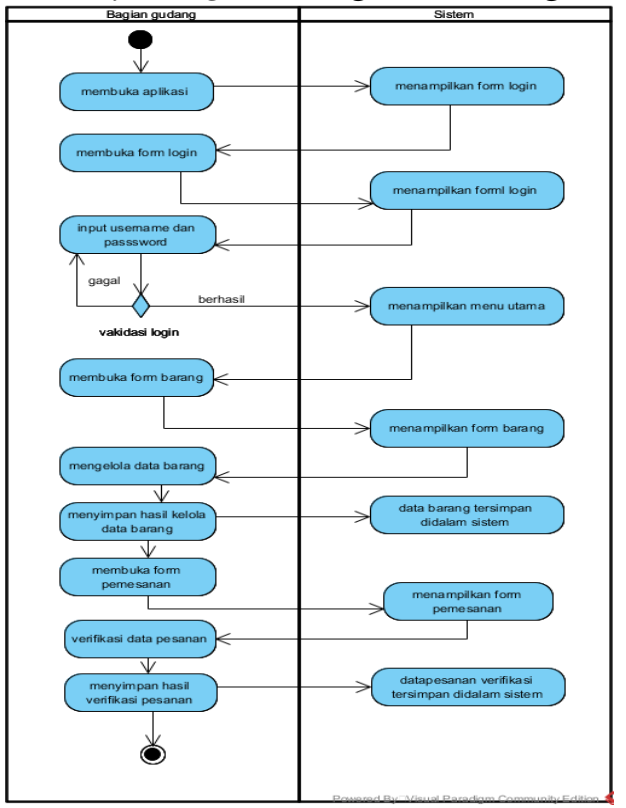

Gambar 5. Diagram Activity Bagian Gudang

Bagian Gudang adalah karyawan CV. Arema Alam Abadi yang bertugas menyiapkan dan mengirimkan barang pesanan Konsumen. Dari Activity Diagram di atas, dapat diketahui bagaimana prosedur Bagian Gudang mengelola data barang. Melalui Sistem Informasi Point of Sales (POS) Pada CV. Arema Alam Abadi ini, diharapkan tidak terjadi lagi kesalahan pengiriman barang, karena data yang diperoleh oleh Bagian Gudang telah diverifikasi oleh Admin melalui sistem.

d) Activity Diagram Distributor

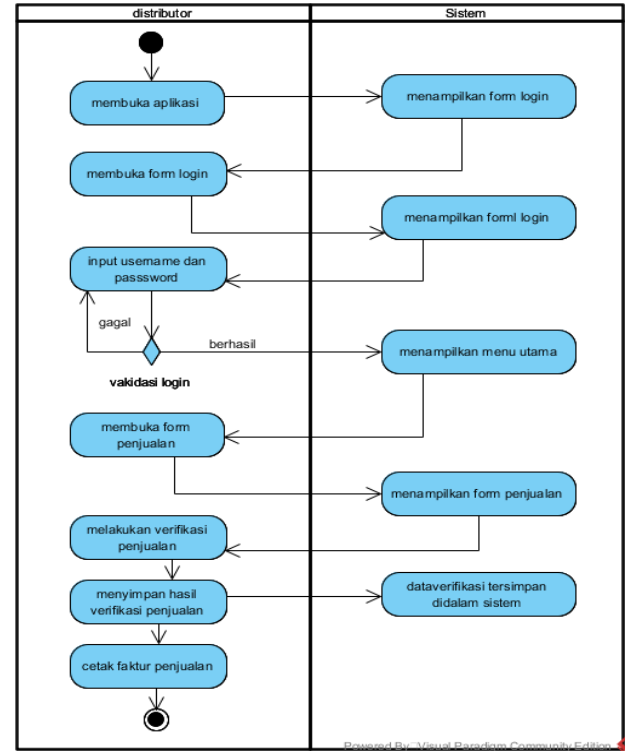

Gambar 6. Activity Diagram

Distributor

Distributor ini adalah mitra CV. Arema Alam Abadi yang bertugas menyiapkan pasokan barang yang akan dijual oleh CV. Arema Alam Abadi. Untuk memudahkan proses pencatatan pengadaan barang, maka Distributor juga dilibatkan dalam sistem. Dari Activity Diagram di atas, dapat diketahui bagaimana prosedur Distributor mengelola data barang yang dipesan oleh Staf Administrasi, yang tentunya sudah disetujui oleh Direktur CV. Arema Alam Abadi.

e) Activity Diagram Direktur

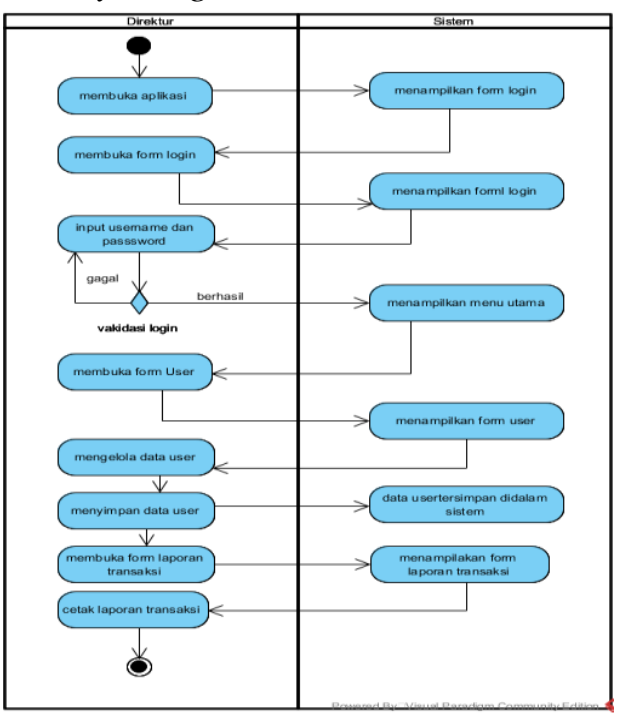

Gambar 7. Activity Diagram Direktur 
Direktur adalah pipinan CV. Arema Alam Abadi. Karena itu, tentu saja memiliki hak akses ke seluruh bagian dari Sistem Informasi Point of Sales Pada CV. Arema Alam Abadi ini. Dari Activity Diagram di atas, dapat diketahui bahwa Direktur dapat mengelola data user yaitu siapa saja yang dapat berinteraksi melalui Sistem Informasi Point of Sales Pada CV. Arema Alam Abadi ini dan memeriksa laporan transaksi yang telah dilaksanakan melalui sistem. Dengan begitu, Staf Administrasi tidak perlu lagi mencetak laporan penjualan untuk kemudian diketahui dan disetujui oleh Direktur, karena Direktur sudah dapat memeriksa laporan-laporan tersebut melalui Sistem Informasi Point of Sales (POS) Pada CV. Arema Alam Abadi ini.

\section{3) Rancangan Basis Data}

Setiap sistem informasi tentu memerlukan basis data sebagai penyimpanan data yang dikelola melalui sistem informasi tersebut. Agar sistem informasi yang dirancang dan dibangun dapat berjalan seperti yang diinginkan, maka basis data juga harus dirancang dengan benar. Adapun rancangan basis data Sistem Informasi Point of Sales (POS) Pada CV. Arema Alam Abadi ini adalah sebagai berikut:

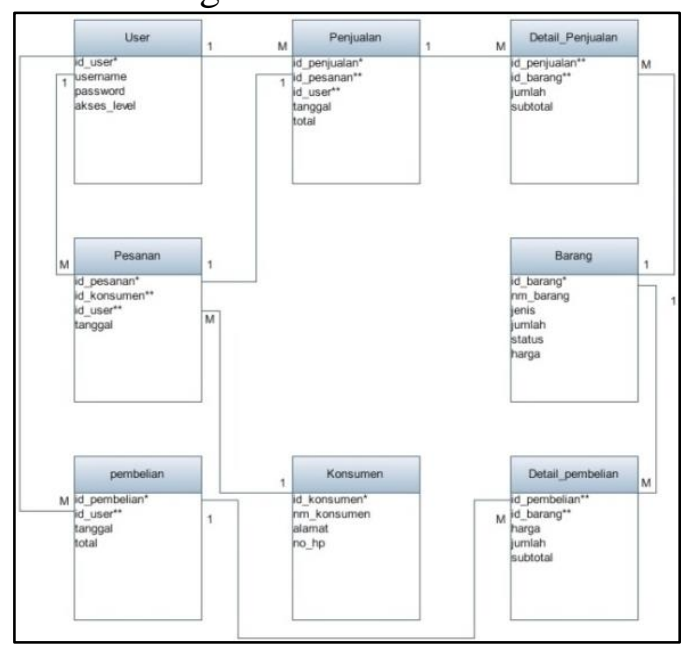

Gambar 8. Rancangan Basis Data (Logical Structure Record)
Tabel-tabel yang terdapat pada rancangan basis data di atas (LRS) merupakan representasi dari objek-objek yang saling berinteraksi pada prosedur sistem yang sedang berjalan pada CV. Arema Alam Abadi serta aktifitas yang menjadi interaksi dari setiap objek tersebut.

4) Spesifikasi File

Agar tabel-tabel yang terdapat pada basis data dapat menyimpan data sesuai dengan yang dibutuhkan oleh sistem, maka perlu dijabarkan spesifikasinya, agar dapat terlihat jelas struktur data yang akan tersimpan dalam file dari masing-masing tabel tersebut.

a) Spesifikasi File User

Nama File : user

Akronim : user.sql

Fungsi : untuk menyimpan data pengguna

Tipe File : File Master

Organisasi File: Indexed Sequential

Akses File : Random

Media : Harddisk

Panjang record: 56

Kunci Field : id_user

Software : MySQL

Tabel IV.18. Spesifikasi File User

\begin{tabular}{|l|c|c|c|}
\hline \multicolumn{1}{|c|}{ Nama Field } & Tipe & Panjang & Ket \\
\hline id_user & Varchar & 6 & Primary Key \\
\hline username & Varchar & 20 & \\
\hline password & Varchar & 20 & \\
\hline akses_level & Integer & 10 & \\
\hline
\end{tabular}

b) Spesifikasi File Pesanan

Nama File : Pesanan

Akronim : pesanan.sql

Fungsi : untuk menyimpan data pemesanan

Tipe File : File Transaksi

Organisasi File: Indexed Sequential

Akses File : Random

Media : Harddisk

Panjang record: 18

Kunci Field : id_pesanan

Software : MySQL

Tabel IV.19. Spesifikasi File Pesanan

\begin{tabular}{|l|c|c|c|}
\hline \multicolumn{1}{|c|}{ Nama Field } & Tipe & Panjang & Ket \\
\hline id_pesanan & varchar & 6 & Primary Key \\
\hline id_user & varchar & 6 & Foreign Key \\
\hline id_konsumen & varchar & 6 & Foreign Key \\
\hline tanggal & date & & \\
\hline
\end{tabular}

Jurnal Teknologi \& Manajemen Informatika - Vol.5 No.2 2019 
c) Spesifikasi File Konsumen

$\begin{array}{ll}\text { Nama File } & \text { : Konsumen } \\ \text { Akronim } & \text { : konsumen.sql } \\ \text { Fungsi } & : \text { untuk menyimpan } \\ & \text { data konsumen } \\ \text { Tipe File } & : \text { FileMaster } \\ \text { Organisasi File } & : \text { Indexed Sequential } \\ \text { Akses File } & : \text { Random } \\ \text { Media } & : \text { Harddisk } \\ \text { Panjang record } & : 71 \\ \text { Kunci Field } & : \text { id_konsumen } \\ \text { Software } & : \text { MySQL }\end{array}$

Tabel IV.20.

Spesifikasi File Konsumen

\begin{tabular}{|l|c|c|c|}
\hline \multicolumn{1}{|c|}{ Nama Field } & Tipe & Panjang & Ket \\
\hline id_konsumen & varchar & 6 & Primary Key \\
\hline nm_konsumen & varchar & 20 & \\
\hline alamat & varchar & 30 & \\
\hline no_hp & varchar & 15 & \\
\hline
\end{tabular}

d) Spesifikasi File Barang

Nama File : Barang

Akronim : barang.sql

Fungsi : untuk menyimpan data barang

Tipe File : File Master

Organisasi File : Indexed Sequential

Akses File : Random

Media : Harddisk

Panjang record : 66

Kunci Field : id_barang

Software : MySQL

Tabel IV.21.

Spesifikasi File Barang

\begin{tabular}{|l|c|c|c|}
\hline \multicolumn{1}{|c|}{ Nama Field } & Tipe & Panjang & Ket \\
\hline id_barang & Varchar & 6 & Primary Key \\
\hline nm_barang & Varchar & 20 & \\
\hline jenis & Varchar & 10 & \\
\hline jumlah & Integer & 10 & \\
\hline status & Varchar & 10 & \\
\hline harga & Integer & 10 & \\
\hline
\end{tabular}

e) Spesifikasi File Penjualan

Nama File : Penjualan

Akronim : penjualan.sql

Fungsi : untuk penyimpanan data penjualan

Tipe File : File Transaksi

Organisasi File : Indexed Sequential

Akses File : Random

Media : Harddisk

Panjang record : 28

Kunci Field : id_penjualan

Software : MySQL
Tabel IV.22.

Spesifikasi File Penjualan

\begin{tabular}{|l|c|c|c|}
\hline \multicolumn{1}{|c|}{ Nama Field } & Tipe & Panjang & Ket \\
\hline id_penjualan & varchar & 6 & Primary Key \\
\hline id_pesanan & varchar & 6 & Foreign Key \\
\hline id_user & varchar & 6 & Foreign Key \\
\hline tanggal & Date & & \\
\hline total & Integer & 10 & \\
\hline
\end{tabular}

f) Spesifikasi File Detail_Penjualan

Nama File : Detail_Penjualan

Akronim : detailpenjualan.sql

Fungsi : untuk menyimpan data detail penjualan

Tipe File : FileMaster

Organisasi File : Indexed Sequential

Akses File : Random

Media : Harddisk

Panjang record : 32

Kunci Field : -

Software : MySQL

Tabel IV.23.

Spesifikasi File Detail Penjualan

\begin{tabular}{|l|c|c|c|}
\hline \multicolumn{1}{|c|}{ Nama Field } & Tipe & Panjang & Ket \\
\hline id_penjualan & Varchar & 6 & Foreign Key \\
\hline id_barang & Varchar & 6 & Foreign Key \\
\hline jumlah & Varchar & 10 & \\
\hline subtotal & Integer & 10 & \\
\hline
\end{tabular}

g) Spesifikasi File Pembelian

Nama File : Pembelian

Akronim : pembelian.sql

Fungsi : Untuk menyimpan data pembelian stok barang

Tipe File : FileMaster

Organisasi File : Indexed Sequential

Akses File : Random

Media : Harddisk

Panjang record : 22

Kunci Field : id_pembelian

Software : MySQL

Tabel IV.24.

Spesifikasi File Pembelian

\begin{tabular}{|l|c|c|c|}
\hline \multicolumn{1}{|c|}{ Nama Field } & Tipe & Panjang & Ket \\
\hline id_pembelian & varchar & 6 & Primary Key \\
\hline id_User & varchar & 6 & Foreign Key \\
\hline tanggal & Date & & \\
\hline total & Integer & 10 & \\
\hline
\end{tabular}

h) Spesifikasi file Detail Pembelian

Nama File : Detail_Pembelian

Akronim : detailpembelian.sql

Fungsi : Untuk menyimpan data detail pembelian

Tipe File : File Transaksi 
Organisasi File : Indexed Sequential

Akses File : Random

Media : Harddisk

Panjang record : 42

Kunci Field : -

Software : MySQL

Tabel IV.25.

Spesifikasi File Detail Pembelian

\begin{tabular}{|l|c|c|c|}
\hline \multicolumn{1}{|c|}{ Nama Field } & Tipe & Panjang & Ket \\
\hline id_pembelian & Varchar & 6 & Foreign Key \\
\hline id_barang & Varchar & 6 & Foreign Key \\
\hline harga & Integer & 10 & \\
\hline jumlah & Integer & 10 & \\
\hline subtotal & Integer & 10 & \\
\hline
\end{tabular}

5) Rancangan Prototype

Setelah melakukan analisis kebutuhan baik itu kebutuhan fungsional dan kebutuhan non fungsional kemudian dirancang pula sistemnya dengan Diagram UML dan rancangan basis data beserta spesifikasi file-nya, maka hasil dari analiis dan rancangan sitem tersebut dijadikan sebagai landasan dalam membangun prototype Sistem Informasi Point of Sales (POS) Pada CV. Arema Alam Abadi. Prototype sistem dibangun dengan bahasa pemrograman Visual Basic.NET, mengingat CV. Arema Alam Abadi menggunakan komputer dengan sistem operasi Windows. Adapun rancangan tampilan beserta fungsifungsinya dari prototype Sistem Informasi Point of Sales (POS) Pada CV. Arema Alam Abadi yang dibangun adalah sebagai berikut:

a) Prototype Tampilan Login

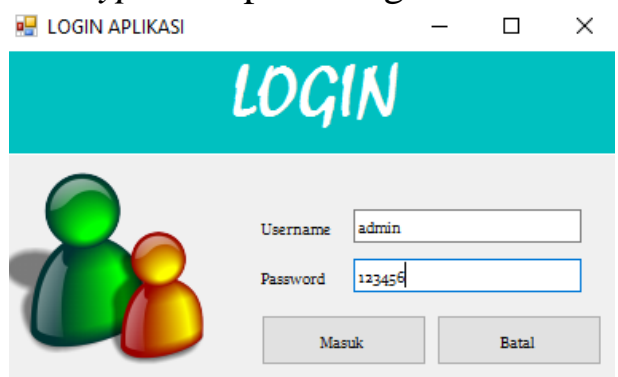

Gambar 9. Prototype Tampilan

Menu Login

Menu login ini adalah menu yang digunakan oleh setiap user yang akan masuk dan menggunakan Sistem Informasi Point of Sales (POS) Pada
CV. Arema Alam Abadi. Agar dapat menggunakan Sistem Informasi Point of Sales (POS) ini, maka user harus membuat akun terlebih dahulu. Jika sudah memiliki akun, maka user dapat masuk dan mengunakan Sistem Informasi Point of Sales (POS) ini melalui menu login dengan cara menginputkan username dan password. Jika username dan/atau password salah, maka user tidak diperkenankan masuk ke sistem. Jika username dan password benar, maka user diperkenankan masuk ke sistem dan dapat menggunakan sistem sesuai dengan tingkat user-nya.

b) Prototype Tampilan Menu Utama Staf Administrasi

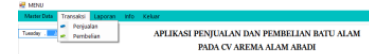

Gambar 10. Prototype Tampilan

Menu Utama Staf Administrasi

Pada Menu Utama Staf Administrasi ini, diketahui bahwa Staf Administrasi dapat mengakses Menu Penjualan dan Pembelian, sesuai dengan deskripsi pekerjaannya di CV. Arema Alam Abadi. Selain itu, Staf Administrasi juga dapat mengakses Menu Laporan, untuk memeriksa kembali Laporan Transaksi sebelum diverifikasi oleh Direktur.

c) Prototype Tampilan Menu Data Barang

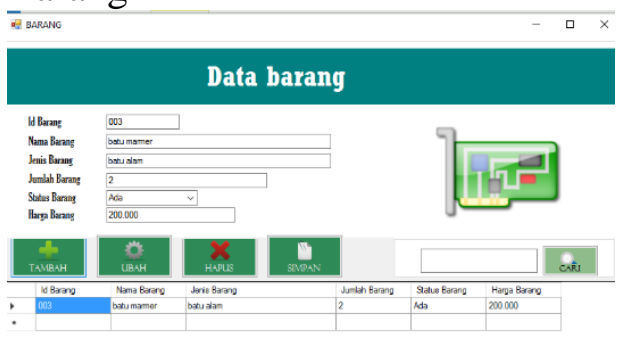

Gambar 11. Prototype Tampilan Menu Barang

Menu Barang ini adalah menu yang dapat diakses oleh Bagian Gudang, dimana pada menu ini Bagian Gudang dapat mengelola data barang yaitu menambah data barang masuk, merubah 
stok data barang (misalnya terjadi kerusakan) dan menghapus data barang yang memang sudah tidak diperjual belikan lagi oleh CV. Arema Alam Abadi.

d) Prototype Tampilan Menu Data Konsumen

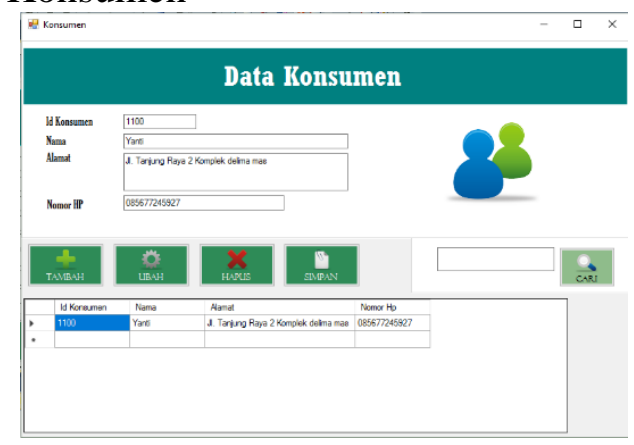

Gambar 12. Prototype Tampilan Menu Data Konsumen

Menu Konsumen ini adalah menu yang dapat diakses oleh Staf Administrasi untuk mendata dan mengelola Data Konsumen. Hal ini tentu saja untuk memudahkan proses pemesanan, konfirmasi pembayaran dan pengiriman barang ke alamat konsumen, agar semua transaksi yang dilakukan oleh konsumen tercatat di sistem dan diverifikasi oleh Staf Administrasi, sehingga mempermudah proses pelaporan yang harus dilakukan oleh Staf Administrasi kepada Direktur CV. Arema Alam Abadi. Dengan tercatatnya semua transaksi di Sistem Direktur juga dapat mengakses data laporan penjualan secara langsung dan real time.

e) Prototype Tampilan Menu Penjualan

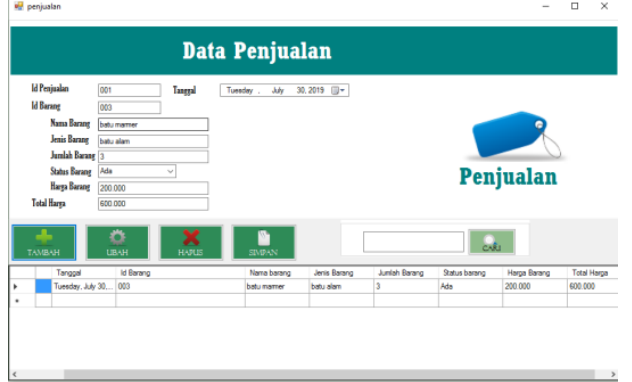

Gambar 13. Prototype Tampilan Menu Penjualan
Menu Penjualan ini adalah menu transaksi yang dapat diakses oleh Staf Administrasi untuk mengelola Data Pesanan Konsumen. Dari menu penjualan ini akan dihasilkan rincian pesanan konsumen, struk penjualan yang akan diberikan kepada konsumen dan laporan penjualan yang akan dilaporkan kepada Direktur CV. Arema Alam Abadi.

f) Prototype Tampilan Menu Laporan Penjualan

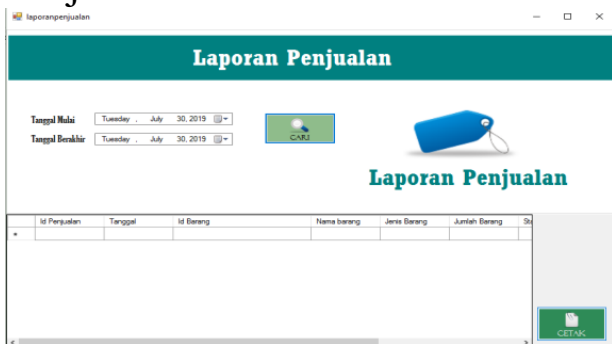

Gambar 14. Prototype Tampilan Menu Laporan Penjualan

Menu Laporan Penjualan ini adalah menu yang dapat diakses oleh Staf Administrasi untuk menampilkan laporan penjualan yang akan dilaporkan kepada Direktur CV. Arema Alam Abadi.

\section{KESIMPULAN}

Dari hasil penelitian dan perancangan Sistem Informasi Point of Sales (POS) Pada CV. Arema Alam Abadi, maka Penulis menarik beberapa kesimpulan, sebagai berikut:

1) Sistem Penjualan dan Pelaporan yang diterapkan Pada CV. Arema Alam Abadi masih bersifat arsip dokumen secara fisik, artinya dalam mengelola data penjualan dan laporan penjualan, perusahaan masih menggunakan sistem pembukuan konvensional, hal ini tentu saja memberi dampak pada berlangsungnya kegiatan yang ada pada perusahaan tersebut, yaitu mengurangi nilai efektifitas dan efesiensi pada proses pengelolaan datanya.

2) Dengan dirancang dan dibangunnya Sistem Informasi Point of Sales (POS) Pada CV. Arema Alam Abadi yang 
terkomputerisasi diharapkan akan dapat membantu dalam mempercepat proses pengelolaan data, khususnya Staf Administrasi, karena Admin memiliki peran krusial dalam pengelolaan data penjualan dan pembuatan laporan.

3) Sistem Informasi Point of Sales (POS) Pada CV. Arema Alam Abadi ini diharapkan dapat meningkatkan efektifitas dan efisiensi di segala aspek pada CV. Arema Alam Abadi, agar dapat meningkatkan pelayanannya bagi masyarakat.

4) Sistem Informasi Point of Sales (POS) Pada CV. Arema Alam Abadi ini dapat memberikan informasi yang lengkap bagi pimpinan perusahaan, karena semua data penjualan dan laporan-laporanya sudah terarsip rapi di dalam sistem, sehingga dapat dengan mudah digunakan untuk pengambilan keputusan demi lancarnya aktifitas perusahaan.

Setelah diterapkannya Sistem Informasi Point of Sales (POS) Pada CV. Arema Alam Abadi yang sudah terkomputerisasi ini, maka terdapat beberapa saran yang Penulis berikan demi kelancaran dalam proses penerapan dan pengembangan sistem ini ke depannya, di antaranya sebagai berikut:

1) Agar dapat diterapkan dengan benar, maka semua pengguna Sistem Informasi Point of Sales (POS) Pada CV. Arema Alam Abadi ini diharapkan untuk mengikuti pelatihan/tutorial pengunaan sistem informasi ini dengan benar.

2) Agar para pengguna menggunakan Sistem Informasi Point of Sales (POS) Pada CV. Arema Alam Abadi ini sesuai dengan petunjuk penggunaan yang sudah disediakan oleh System Developer, agar menghasilkan output yang benar pula dari setiap data yang diinputkan, terutama bagi karyawan baru yang tidak mengikuti pelatihan/tutorial penggunaan Sistem Informasi Point of Sales (POS) Pada CV. Arema Alam Abadi ini.

3) Lakukan back-up data secara berkala, agar terhindar dari kerusakan dan/atau kehilangan data ketika terjadi kerusakan pada komputer yang digunakan.

4) Para pengguna diharapkan untuk selalu me-maintenance komputer yang digunakan untk menghindari kerusakan yang dapat mengakibatkan terganggunya sistem operasi komputer sehingga Sistem Informasi Point of Sales (POS) Pada CV. Arema Alam Abadi tidak dapat digunakan.

5) Para pengguna juga diharapkan mendokumentasikan keluhan-keluhan yang bersifat sistematis, agar menjadi masukan untuk perbaikan Sistem Informasi Point of Sales (POS) Pada CV. Arema Alam Abadi ini.

6) Jika para pengguna sudah familiar dengan Sistem Informasi Point of Sales (POS) Pada CV. Arema Alam Abadi ini, maka ada baiknya sistem dikembangkan ke bentuk platform yang lebih canggih lagi, misalnya sistem informasi berbasis website bahkan berbasis mobile.

\section{REFERENSI}

[1] Atmoko, Eko Hari. 2015 Program Akuntansi Beserta Manajemen Aset Menggunakan VB dan SQL Server. Jakarta: PT Elex Media Komputindo

[2] Djahir, Yulia dan Dewi Pratita. 2015. Bahan Ajar Sistem Informasi Manajemen. Yogyakarta: CV. Budi Utama.

[3] Hutahaean, Jeperson. 2015. Konsep Sistem Informasi. Yogyakarta: CV. Budi Utama.

[4] Jogiyanto, H.M. 2015. Analisis dan Desain Sistem Informasi. Yogyakarta: CV. Andi Offset.

[5] Khairuzzaman, Muhammad Qadafi. Nasihin, Muhamad. Setiawan, Heru. 2014. Perancangan Sistem Penjualan Batu Permata Berbasis Web Pada Toko Batu Permata Dan Mulia Redha Collection. Konferensi Nasional Ilmu Sosial dan Teknologi. 
[6] Kristanto, Andi. 2015. Perancangan Sistem Informasi. Yogyakarta: Gava Media.

[7] Ladjamudin, Al-Bahra Bin. 2015. Analisis dan Desain Sistem Informasi. Yogyakarta: Graha Ilmu.

[8] Lubis, Adyanata. 2016. Basis Data Dasar. Yogyakarta: CV. Budi Utama.

[9] Rosa, A.S. dan Shalahuddin, M. 2015. Kolaborasi Rekayasa Perangkat Lunak Terstruktur dan Berorientasi Objek. Bandung: Informatika.

[10] Sihombing, Daniel Oktodeli. Nugraha, Wahyu. Amdani, Farida. 2016. Aplikasi pengelolaan data order mkios berbasis web pada TDC PT. Talesindo Shop Pontianak. SIMNASIPTEK. 